\title{
Adherence of Patients with Diabetes to a Lifestyle Advice and Management Plan in Basra, Southern Iraq
}

\author{
Rawnaq Adil Aladhab ${ }^{a}$ Majid Hameed Alabbood ${ }^{\text {b, c }}$ \\ a Department of Pharmacology and Toxicology, College of Pharmacy, University of Basrah, Basrah, Iraq; \\ ${ }^{\mathrm{b}}$ The Specialized Endocrine and Diabetes Center, Almawani Teaching Hospital, Basrah, Iraq; \\ 'Alzahraa Medical College, University of Basrah, Basrah, Iraq
}

\section{Keywords}

Diabetes · Adherence · Therapy · Diet · Physical activity

\begin{abstract}
Background: Poor adherence to treatment regimens is a complex problem, especially for those with chronic illnesses. Noncompliance is believed to be the most common reason for treatment failure in diabetic patients, leading to the absence of metabolic control and accelerating disease-related complications. Data on the adherence of people with diabetes in Iraq are lacking. Objectives: The purpose of this study was to measure the rate of adherence among Iraqi patients with diabetes. Methods: This was a cross-sectional study conducted in the Specialized Endocrine and Diabetes Center in Basra, southern Iraq, during the period from June to August 2018. Data were collected by completing an interviewing questionnaire consisting of 13 questions. Results: A total of 231 patients were included in the study $(54.5 \%$ were female). Mean age was $51.85 \pm 13.55$ years. $65.4 \%$ of the participants were taking their medications at the right times. The most common reason for not taking their medication $(48.8 \%)$ was difficulty in remembering the dosage times. $40.7 \%$ of the participants were sedentary. Only one-third of the patients followed their doctors' instructions regarding diet. Conclusions: The rate of adherence to medication reg-
\end{abstract}

imens and lifestyle advice was unsatisfactory in this study group. The awareness of diabetic patients and their caring physicians about the importance of adherence to therapy, exercise, and diet should be emphasized.

(C) 2019 The Author(s)

Published by S. Karger AG, Basel

\section{Introduction}

The prevalence of type 2 diabetes is increasing globally and has become a serious public health problem [1]. The worldwide prevalence of type 2 diabetes is predicted to rise from 425 million people in 2017 to 629 million people by 2045 [2]. Furthermore, diabetes is presently among the 5 highest causes of death in most high-income countries; it resulted in 4.6 million deaths internationally in 2011 [3]. Half of patients with type 2 diabetes fail to achieve adequate glycemic control, i.e. glycated hemoglobin $\left(\mathrm{HbA}_{1 \mathrm{c}}\right)<7 \%$ [4].

Effective management of diabetes depends on patients' self-care [5]. Compliance may be a key part of health care and affects all areas [6]. Poor adherence to treatment regimens is a complex problem, especially for those with chronic illnesses, and it is undermining the advantages of medical care considerably [7].

\section{KARGER}

E-Mail karger@karger.com www.karger.com/ijd (c) 2019 The Author(s) Published by S. Karger AG, Basel

Karge

Open access

This article is licensed under the Creative Commons AttributionNonCommercial-NoDerivatives 4.0 International License (CC BYNC-ND) (http://www.karger.com/Services/OpenAccessLicense). Usage and distribution for commercial purposes as well as any distribution of modified material requires written permission.
Rawnaq Adil Aladhab

Department of Pharmacology and Toxicology, College of Pharmacy

University of Basrah, Garmat Ali Street, 12

Garmat Ali, 61004 Basra (Iraq)

E-Mail rawnaqaladhab2019@yahoo.com 
Table 1. Basic characteristics of the 231 participants

\begin{tabular}{|c|c|c|}
\hline Variable & $N$ & $\%$ \\
\hline \multicolumn{3}{|l|}{ Age group } \\
\hline $18-29$ years & 12 & 5.2 \\
\hline $30-39$ years & 28 & 12.1 \\
\hline $40-49$ years & 39 & 16.9 \\
\hline $50-59$ years & 89 & 38.5 \\
\hline $60-69$ years & 37 & 16 \\
\hline$\geq 70$ years & 26 & 11.3 \\
\hline \multicolumn{3}{|l|}{ Gender } \\
\hline Male & 105 & 45.5 \\
\hline Female & 126 & 54.5 \\
\hline \multicolumn{3}{|l|}{ Marital status } \\
\hline Married & 198 & 85.7 \\
\hline Single & 15 & 6.5 \\
\hline Divorced & 3 & 1.3 \\
\hline Widowed & 15 & 6.5 \\
\hline \multicolumn{3}{|l|}{ Residence } \\
\hline Rural & 91 & 39.4 \\
\hline Urban & 140 & 60.6 \\
\hline \multicolumn{3}{|l|}{ Education } \\
\hline Illiterate & 55 & 23.8 \\
\hline Primary school & 79 & 34.2 \\
\hline Secondary school & 88 & 38.1 \\
\hline College and above & 9 & 3.9 \\
\hline \multicolumn{3}{|l|}{ Monthly income } \\
\hline Low & 165 & 71.4 \\
\hline Medium & 61 & 26.4 \\
\hline High & 5 & 2.2 \\
\hline \multicolumn{3}{|l|}{ Duration of diabetes } \\
\hline$<5$ years & 80 & 34.6 \\
\hline 5-9 years & 65 & 28.1 \\
\hline $10-14$ years & 53 & 22.9 \\
\hline$\geq 15$ years & 33 & 14.3 \\
\hline \multicolumn{3}{|l|}{ Type of diabetes } \\
\hline Type 1 & 27 & 11.7 \\
\hline Type 2 & 204 & 88.3 \\
\hline \multicolumn{3}{|l|}{ Treatment of diabetes } \\
\hline Diet & 5 & 2.2 \\
\hline Oral antidiabetic & 115 & 49.8 \\
\hline Insulin & 35 & 15.2 \\
\hline A combination (oral + insulin) & 76 & 32.9 \\
\hline
\end{tabular}

There are different definitions of compliance; one is the degree to which the patient's real history of drug administration corresponds to the prescribed regimen [8]. Another is the degree to which a patient's conduct, in terms of taking their medication, following a recommended diet, or implementing lifestyle changes, goes along with medical advice [9]. Noncompliance is believed to be the most common reason for treatment failure. In addition, noncompliance leads to the absence of meta-
Table 2. Compliance of diabetic patients and reasons for noncompliance $(n=231)$

\begin{tabular}{lrr}
\hline & $N$ & $\%$ \\
\hline Taking medication on time & & \\
$\quad$ Yes & 151 & 65.4 \\
No & 80 & 34.6 \\
\hline Reasons for not taking medication at the right time & \\
Cost & 5 & 63 \\
Drug unavailability & 11 & 13.8 \\
Difficult to remember & 39 & 48.8 \\
Because of my job & 6 & 7.5 \\
I don't care & 13 & 16.3 \\
Insulin was ineffective & 6 & 7.5 \\
Total & 80 & 100 \\
\hline Activity level & & \\
Sedentary & 94 & 40.7 \\
Mild & 50 & 21.6 \\
Moderate & 62 & 26.8 \\
Active & 25 & 10.8 \\
\hline Adherence to dietary instructions & & \\
Yes & 88 & 38.1 \\
Sometimes & 61 & 26.4 \\
No & 82 & \\
\hline
\end{tabular}

bolic control which contributes to the development and acceleration of diabetes complications [10-12].

Adherence rates are typically lower for patients with chronic conditions than for those with acute conditions [13]. Such decreased adherence not only results in unwanted health outcomes, it also has a significant impact on the cost of healthcare [14].

There are several techniques used to measure compliance; self-reports and interviews with patients are considered the most common techniques for this purpose [15]. There are several studies from different parts of the world that have tried to measure the treatment compliance of people with diabetes. However, data from Iraq are lacking. Therefore, we conducted a questionnaire-based interview with patients afflicted by diabetes to measure the rate of their adherence to lifestyle and management advice supplied by their health care providers.

\section{Design and Methods}

This was a cross-sectional study conducted on patients with diabetes attending the Specialized Endocrine and Diabetes Center in Basra, southern Iraq, during the period from June to August 2018. All people with diabetes attending the center on the day of 
Table 3. Relationship between educational level of participants and physical activity $(n=231)$

\begin{tabular}{|c|c|c|c|c|c|}
\hline \multirow[t]{2}{*}{ Education } & \multicolumn{5}{|c|}{ Physical activity } \\
\hline & sedentary & mild & moderate & active & total \\
\hline Illiterate & $33(60.0)$ & $9(16.4)$ & $8(14.5)$ & $5(9.1)$ & $55(100)$ \\
\hline Primary school & $32(40.5)$ & $16(20.3)$ & $26(32.9)$ & $5(6.3)$ & $79(100.0)$ \\
\hline Secondary school & $27(30.7)$ & $23(26.1)$ & $24(27.3)$ & $14(15.9)$ & $88(100.0)$ \\
\hline College and above & $2(22.2)$ & $2(22.2)$ & $4(44.4)$ & $1(11.1)$ & $9(100.0)$ \\
\hline Total & $94(40.7)$ & $50(21.6)$ & $62(26.8)$ & $25(10.8)$ & $231(100.0)$ \\
\hline
\end{tabular}

Values represent $n(\%) . p<0.05$

Fig. 1. Relationship between age and physical activity $(p=0.000)$.

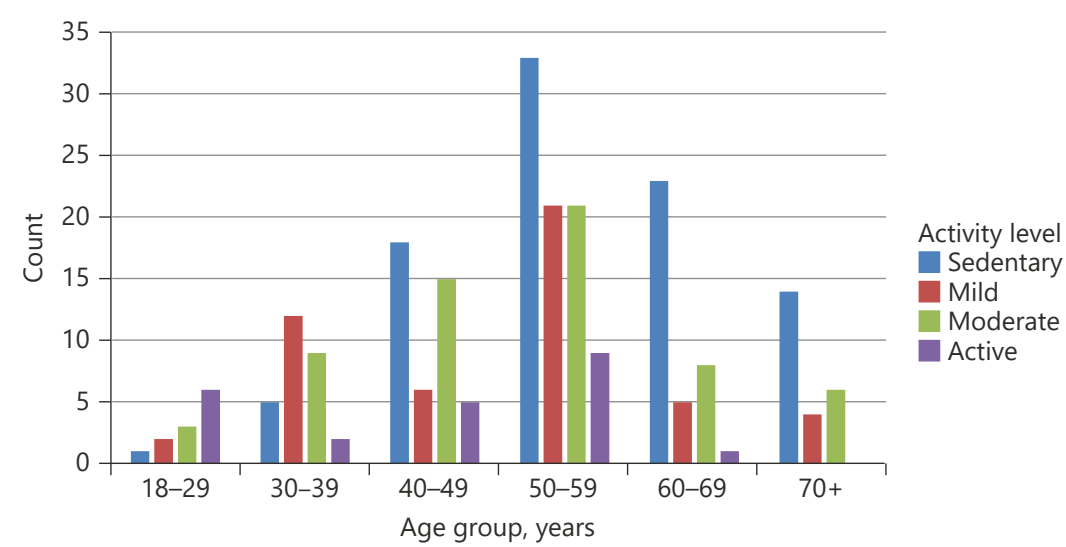

the interview who agreed to participate in the study were included after taking an informed consent from each participant.

The data were collected for each patient by completing an interviewing questionnaire. The questionnaire was validated. Data were collected by face-to-face interviews with the patients by the investigators. There were 13 questions and the following data were collected: age, gender, address, marital status, smoking, educational level, monthly income, type and duration of the diabetes, and treatment type (insulin, an oral antidiabetic drug [OAD], or a combination of the 2).

The other part of the questionnaire was about compliance regarding taking their medications as prescribed and on time, adherence to a dietary regimen as advised by the health care provider, questions about self-care and physical activity, and recording the level of $\mathrm{HbA}_{1 \mathrm{c}}$ from the last visit. Finally, the participants were asked about the frequency of $\mathrm{HbA}_{1 \mathrm{c}}$ measurements and their selfmonitoring of blood glucose (SMBG) at home.

Patient adherence to medications was measured by the recall method and recording the number of missed doses over 15 days prior to the date of the interview. Failure to take $>2$ doses over the last 15 days was considered as nonadherence. All the participants had received a written dietary plan as part of the usual care provided at the center prior to the interview. Physical activity was classified as the following: active for those who exercised for $\geq 30 \mathrm{~min} /$ day, moderate for those who exercised for 15-30 min/day, mild for those who exercised for $<15$ min a day, and sedentary for those who do not exercise at all.

\section{Statistical Analysis}

Categorical variables are presented as frequencies and percentages. Numerical variables are reported as the mean \pm standard deviation. The $\chi^{2}$ test was used to test the correlation between variables except for tables with small frequencies, where the Fisher exact test was used. $p<0.05$ was considered significant. Data analysis was performed by means of SPSS for Windows (Statistical Package for Social Sciences) v25.

\section{Results}

A total of 231 patients were included in the study. Of these, $54.5 \%$ were female. The participants' age ranged from 18 to 91 years (mean $51.85 \pm 13.55$ years). Those in the age group of $50-59$ years represented $38.5 \%$ of the participants. Those from urban areas represented $60.6 \%$. The majority of the patients were married (85.7\%). Illit- 


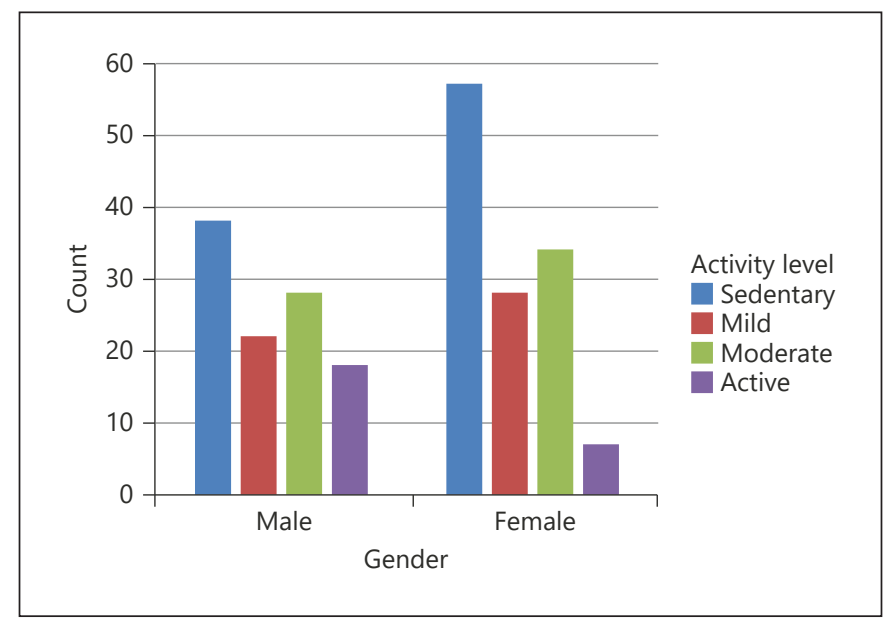

Fig. 2. Relationship between gender and physical activity ( $p=$ 0.036).

Table 4. Relationship between monthly income and whether not patients followed dietary advice $(n=231)$

\begin{tabular}{lcccr}
\hline \multirow{2}{*}{$\begin{array}{l}\text { Monthly } \\
\text { income }\end{array}$} & \multicolumn{4}{l}{ Followed dietary advice } \\
\cline { 2 - 5 } & yes & sometimes & no & \multicolumn{1}{c}{ total } \\
\hline Low & $53(32.1)$ & $45(27.3)$ & $67(40.6)$ & $165(100)$ \\
Medium & $32(52.5)$ & $14(23)$ & $15(24.6)$ & $61(100)$ \\
High & $3(60)$ & $2(40)$ & $0(0)$ & $5(100)$ \\
Total & $88(38.1)$ & $61(26.4)$ & $82(35.5)$ & $231(100)$ \\
\hline
\end{tabular}

Values represent $n(\%) \cdot p=0.013$.

eracy was prevalent in $23.8 \%$. Approximately two-thirds of the participants had a low income. Patients with type 2 diabetes comprised $88.3 \%$. Half of the participants were on an OAD (Table 1).

We found that $65.4 \%$ of the participants were taking their medications at the right time. The most common reason for not taking their medication $(48.8 \%)$ was the difficulty of remembering the dosage times. Regarding physical activity, $40.7 \%$ of the participants were sedentary and only $10.8 \%$ were active. Only one-third of the patients followed their doctors' instructions regarding diet (Table 2).

On further analysis of the data, we found that half of the patients in the age group of 18-29 years were active compared to $11.4 \%$ in the age group of $40-49$ years (Fig. 1).

Illiterate patients were more likely to be sedentary than those who had finished secondary school or college $(p<$

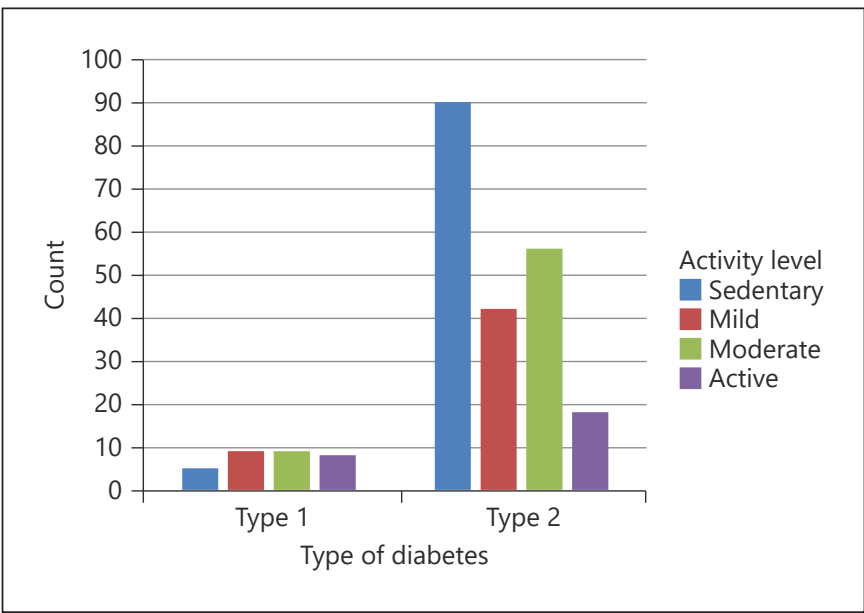

Fig. 3. Relationship between type of diabetes and physical activity $(p=0.006)$.

Table 5. Relationship between monthly income and physical activity in 231 patients

\begin{tabular}{|c|c|c|c|c|c|}
\hline \multirow{2}{*}{$\begin{array}{l}\text { Monthly } \\
\text { income }\end{array}$} & \multicolumn{5}{|c|}{ Physical activity } \\
\hline & sedentary & mild & moderate & active & total \\
\hline Low & $78(47.3)$ & $32(19.4)$ & $40(24.2)$ & $15(9.1)$ & $165(100)$ \\
\hline Moderate & $14(23)$ & $17(27.9)$ & $20(32.8)$ & $10(16.4)$ & $61(100)$ \\
\hline High & $2(40)$ & $1(20)$ & $2(40)$ & $0(0)$ & $5(100)$ \\
\hline Total & $94(40.7)$ & $50(21.6)$ & $62(26.8)$ & $25(10.8)$ & $231(100)$ \\
\hline
\end{tabular}

Values represent $n$ (\%). $p=0.025$.

0.05; Table 3). Furthermore, males were more likely to be physically active than females, and those with type 1 diabetes more than those with type 2 diabetes (Fig. 2, 3).

We found that participants with a high monthly income were more likely to follow dietary advice $(p<0.05$; Table 4). Those with an average income tended to be more active than those with a high or low income $(p<$ 0.05; Table 5).

There was no significance relationship between age, gender, residential area (urban/rural), type and duration of diabetes, income, type of medication, or education level, and whether a patient took their medication on time. Similarly, there was no significant relationship between age, gender, residential area, type and duration of diabetes, or education level, and following their dietary instructions. Likewise, residential area and duration of diabetes had no effect on physical activity. 


\section{Discussion}

This study was conducted in the Specialized Endocrine and Diabetes Center in Basra, Southern Iraq on 231 diabetic patients to assess their compliance to diabetes management.

We found that approximately two-third of the participants were taking their medication at the right times. This is similar to 2 studies from Egypt and Saudi Arabia which revealed that about 57 and $67.9 \%$ of patients always took their medications, as prescribed and on time, respectively $[16,17]$. This rate is unsatisfactory and represents a challenge in achieving treatment goals, and thus plays a major role in the failure to achieve a target $\mathrm{HbA}_{1 c}$. Difficulty remembering the dosage time was the reason for not taking medication on time in about half of the participants in our study. This reflects the importance of using less complicated treatment regimens such as those with fewer pills and fewer insulin injections. This may be achieved by using single or twice-daily basal or biphasic insulin instead of basal-bolus insulin, if possible. Likewise, the use of combination pills instead of multiple separated pills is preferable.

In contrast to our study, greater adherence to therapy was demonstrated in studies conducted in southern India and the UAE, i.e., 84 and $83.6 \%$, respectively $[18,19]$.

An interesting finding in this study was the low rate of adherence to dietary and physical activity advice. Only 38.1 and $10.8 \%$ of the participants followed the prescribed diet and exercise schedule, respectively; this is similar to the results of 36.4 and $27.0 \%$, respectively, in Mukherjee et al. [20]. This may have been due to the lack of awareness among the patients about the importance of lifestyle in diabetes management, and that diet and exercise with pharmacotherapy represent the triangle of this management. It could also be attributed to the failure of health care providers to emphasize the importance of these 2 measures in the management plan.

As expected, younger patients tended to be more active than older ones. This was clearly due to the greater presence of comorbidities such as cardiovascular disease and joint problems in the elderly.

There was a significant association between physical activity and the level of education. As the level of education increased, the physical activity increased. Educated people are more aware of the health benefits of physical activity. This is in line with Gimenes et al. [21], who found that highly educated patients were more adherent to therapy and physical activity advice.

Following dietary advice was significantly lower among those with a low monthly income. This is similar to the study by Mukherjee et al. [20]. Following a special diet is usually more expensive than eating ordinary available food and this can add to the cost burden for patients with diabetes.

Similarly, there was a significant relationship between gender and physical activity. Males were more physically active than females. In a typical Middle Eastern community, exercise is considered inappropriate for women and there are cultural constrains that prohibit females from exercising in public. Similar to Gimenes et al. [21], we found a significant relationship between age and physical activity. Elderly people are more likely to be physically inactive due to a lack of energy, the presence of comorbidities, and musculoskeletal problems.

Regarding the effect of gender on patients' compliance to drug therapy, no difference was demonstrated in our study. This is in line with Arifulla et al. [18].

Surprisingly, there was no significant relationship between the duration of diabetes and adherence to drug therapy. This contrasts with the common belief that the longer the duration of the chronic disease, the lower the adherence rate.

The strength of this study is the large study sample and that it is the first study from Iraq to measure the adherence of people with diabetes, not only to their medications, but also to their lifestyle advice and follow-up plan. There are several limitations. First, it was conducted in a single center; second, it was a questionnaire-based study; and third, there was the possibility of recall bias by the patients.

\section{Conclusion}

We found that the adherence of the patients to medication and lifestyle advice was unsatisfactory. Not remembering the dosing time was the single most important cause for poor adherence to therapy. We recommend increasing the awareness of people with diabetes about the importance of good control achieved by adherence to their therapy as advised by their health care provider as well the importance of regular exercise and diet. Physicians should prescribe simpler insulin regimens such as single or twice-daily doses of basal or premixed insulin, if possible, and use combination tablets instead of multiple $\mathrm{OAD}$. Our findings may represent a baseline data for future larger studies or to test the effect of implementing the recommended measures on improving the adherence rate. 


\section{Acknowledgement}

I would like to thank all the patients who participated in the study. Dr. Rawnaq Adil Aladhab and Dr. Majid Alabbood are the guarantors of this work and, as such, had full access to all the data in the study and take responsibility for the integrity of the data and the accuracy of the data analysis.

\section{Statement of Ethics}

This study was approved by the ethics committee of Basra Health Directorate with the approval No. 286 on 18/4/2018. The authors have no ethical conflicts to disclose.

\section{Disclosure Statement}

No conflicts of interest relevant to this article were reported.

\section{Funding Sources}

There was no funding.

\section{Author Contributions}

R.A.A. and M.A. designed the study, collected and interpreted the data, performed the statistical analysis, and wrote the paper.

\section{References}

1 Cheung BM, Ong KL, Cherny SS, Sham PC, Tso AW, Lam KS. Diabetes prevalence and therapeutic target achievement in the United States, 1999 to 2006. Am J Med. 2009 May; 122(5):443-53

2 Cho NH, Shaw JE, Karuranga S, Huang Y, da Rocha Fernandes JD, Ohlrogge AW, et al. IDF Diabetes Atlas: global estimates of diabetes prevalence for 2017 and projections for 2045 . Diabetes Res Clin Pract. 2018 Apr;138:27181.

3 Aguiree F, Brown A, Cho NH, Dahlquist G, Dodd S, Dunning T, et al. IDF diabetes atlas. 2013.

4 Ali MK, McKeever Bullard K, Imperatore G, Barker L, Gregg EW; Centers for Disease Control and Prevention (CDC). Characteristics associated with poor glycemic control among adults with self-reported diagnosed diabetes-National Health and Nutrition Examination Survey, United States, 2007-2010. MMWR Suppl. 2012 Jun;61(2):32-7.

5 Lai WA, Chie WC, Lew-Ting CY. How diabetic patients' ideas of illness course affect non-adherent behaviour: a qualitative study. Br J Gen Pract. 2007 Apr;57(537):296-302.

6 Chatterjee JS. From compliance to concordance in diabetes. J Med Ethics. 2006 Sep; 32(9):507-10.

7 Vermeire E, Hearnshaw H, Van Royen P, Denekens J. Patient adherence to treatment: three decades of research. A comprehensive review. J Clin Pharm Ther. 2001 Oct;26(5): $331-42$.
8 Urquhart J. Patient non-compliance with drug regimens: measurement, clinical correlates, economic impact. Eur Heart J. 1996; 17(suppl_A):8-15.

9 Haynes R. Determinants of compliance: The disease and the mechanics of treatment. Compliance in health care. Baltimore (MD): Johns Hopkins University Press; 1979.

10 Col N, Fanale JE, Kronholm P. The role of medication noncompliance and adverse drug reactions in hospitalizations of the elderly. Arch Intern Med. 1990 Apr;150(4):841-5

11 Nuesch R, Schroeder K, Dieterle T, Martina B, Battegay E. Relation between insufficient response to antihypertensive treatment and poor compliance with treatment: a prospective case-control study. BMJ. 2001 Jul; 323(7305):142-6.

12 Hughes D, Manns B. Patient compliance with drug therapy for diabetic nephropathy. CMAJ. 2000 May;162(11):1553-4.

13 Osterberg L, Blaschke T. Adherence to medication. N Engl J Med. 2005 Aug;353(5):48797.

14 WHO. Diet, nutrition, and the prevention of chronic diseases: report of a joint WHO/FAO expert consultation. Geneva: World Health Organisation; 2003.

15 Girerd X, Hanon O, Anagnostopoulos K, Ciupek C, Mourad J, Consoli S. Assessment of antihypertensive compliance using a self-administered questionnaire: development and use in a hypertension clinic. Paris: Presse medicale; 1983.
16 Ibrahim NK, Attia SG, Sallam SA, Fetohy EM El-Sewi F. Physicians' therapeutic practice and compliance of diabetic patients attending rural primary health care units in Alexandria. J Family Community Med. 2010 Sep;17(3): 121-8.

17 Khan AR, Al-Abdul Lateef ZN, Al Aithan MA, Bu-Khamseen MA, Al Ibrahim I, Khan SA. Factors contributing to non-compliance among diabetics attending primary health centers in the Al Hasa district of Saudi Arabia. J Family Community Med. 2012 Jan;19(1): 26-32.

18 Arifulla M, John LJ, Sreedharan J, Muttappallymyalil J, Basha SA. Patients' adherence to anti-diabetic medications in a hospital at $\mathrm{Aj}$ man, UAE. Malays J Med Sci. 2014 Jan;21(1): 44-9.

19 Rao CR, Kamath VG, Shetty A, Kamath A. Treatment compliance among patients with hypertension and type 2 diabetes mellitus in a coastal population of Southern India. Int $J$ Prev Med. 2014 Aug;5(8):992-8.

20 Mukherjee S, Sharmasarkar B, Das KK, Bhattacharyya A, Deb A. Compliance to anti-diabetic drugs: observations from the diabetic clinic of a medical college in kolkata, India. J Clin Diagn Res. 2013 Apr;7(4):661-5.

21 Gimenes HT, Zanetti ML, Haas VJ. Factors related to patient adherence to antidiabetic drug therapy. Rev Lat Am Enfermagem. 2009 Jan-Feb;17(1):46-51 